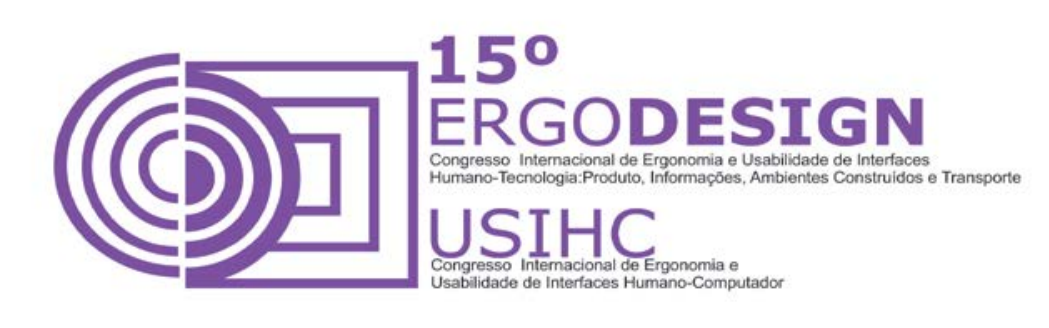

\title{
A ERGONOMIA E A HEDONOMIA COMO CONCEITOS NO DESENVOLVIMENTO DE UMA INTERFACE WEB
}

\section{ERGONOMICS AND THE CONCEPTS IN HEDONOMIA AS DEVELOPMENT OF A WEB INTERFACE}

\author{
SCHULENBURG, Haro (1); \\ BUCHINGER, Talissonn (2); \\ EVERLING, Marli (3); \\ FIALHO, Francisco (2);
}

(1) Univille, Mestre.

e-mail: haro@univille.br

(2) Univille, Graduado.

e-mail: talissonn.dasilva@gmail.com

(3) Univille, Doutora.

e-mail: meverling@gmail.com

(4) UFSC, Doutor.

e-mail: fapfialho@gmail.com

\begin{abstract}
RESUMO
Com o mundo digital cada vez mais presente na vida das pessoas a facilidade de informação e de conhecimento está cada vez maior, mas mesmo com tanta facilidade na busca de informação o tempo para pesquisar em vários website tem diminuído, fazendo com que o usuário muitas vezes não consiga absorver toda a informação que almeja.
\end{abstract}

Palavras-chave: Ergonomia, Hedonomia e Interface web. 


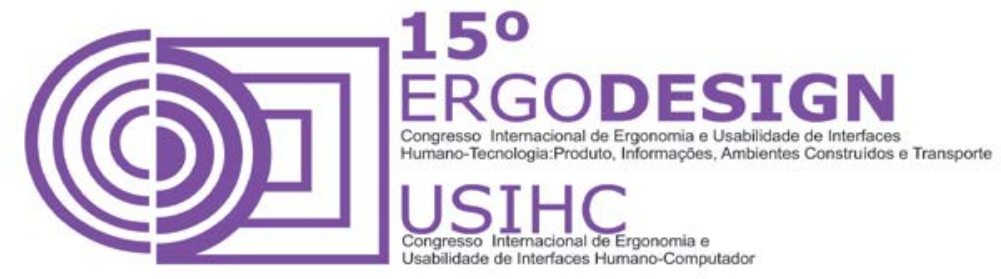

With the digital world increasingly present in people's lives ease of information and knowledge is growing , but even with such ease in finding the time to research information on various website has decreased, causing the user often can not absorb all the information they crave.

Keywords: Ergonomics, Hedonomy and Web Interface.

\section{EXPERIÊNCIA DO USUÁRIO}

Com os produtos cada vez mais inovadores a participação do usuário no desenvolvimento de um projeto fica ainda mais importante. Segundo Cybis et. al (2010) experiência do usuário surge com a interação do homem com a tecnologia proporcionando uma visão abrangente entre as propriedades estéticas, funcionais e de interação com o produto da maneira que as pessoas respondem com aspectos, físicos, emocionais e cognitivos. GARRET (2011) explica que todo produto tende a gerar uma experiência para o usuário, tanto uma experiência satisfatória ou não. $O$ autor ainda define que quanto mais complexo é o produto, mais difícil de ter sucesso na experiência do usuário.

Para que o usuário tenha uma experiência exemplar, Nilsen-Norman Group (2014, web) afirma que o projeto tem que atender as necessidades específicas do usuário, sem barulho ou incomodar. $O$ autor ainda explica que em seguida vem a simplicidade e a elegância que geram satisfação, emoções afetivas e experiências com o produto, dando mais alegria para usarem e navegarem. É a boa experiência que faz com que sua empresa se diferencie das concorrentes e que determina se 0 usuário irá voltar ou não (GARRET 2011).

Royo (2008) aborda que para o usuário o que realmente interessa é que a ação seja realizada de forma clara, simples e rápida que atenda suas necessidades. O autor ainda discute que o usuário ao interagir com uma interface gráfica cria um modelo mental, um cenário cognitivo dos elementos que surgem em sua frente, assim obtendo diferentes tipos de informação, como mostra a figura 1.

\section{Informações}

Informações Sequencial: Quando o site e seu ambiente estabelecem-se como uma sequência; ao ler, o usuário pode prever os eventos em função dessa sequência.

Informações Hierárquica: Atribuindo uma ordem de prioridades aos elementos da página e niveis de leitura e atuaçăo sobre a mesma.

Informação Funcional: Dando uma possivel tarefa para cada um dos elementos que aparecem na tela: ícones, botǒes, imagens, texto, etc.

Informação Perceptiva: Dos elementos visuais do website. Cor, tipografia, contraste, titulos, sua identidade.

Figura 1: Modelo Mental

Fonte: Adaptado de Royo, (2008, p. 98.) 


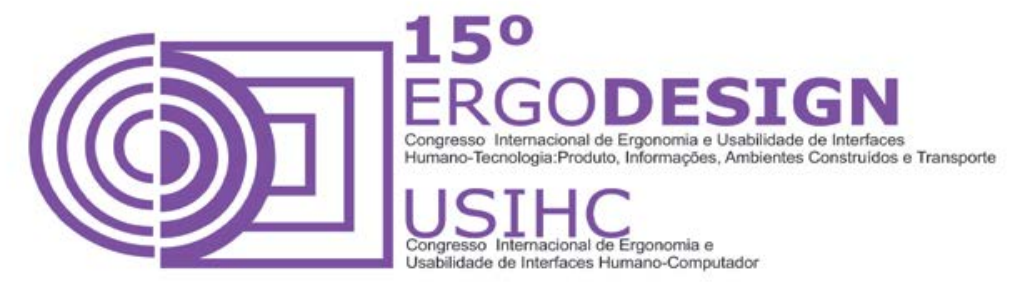

Este modelo mental é um mecanismo que auxilia o usuário em suas ações, servem como guia para buscar a atenção dos usuários, quanto seus interesses na navegação e também uma forma de armazenar informação, podendo definir uma linha gradual de usuários experientes, até inexperientes (ROYO 2008).

Royo (2008) ainda aborda que um usuário inexperiente só consegue adquirir seu aprendizado enquanto navega, assim formando experiências sensoriais e também emocionais com uma navegação constante.

Estas experiências emocionais e sensoriais Preece et. al. (2013) exemplificam as metas da experiência do usuário, onde elas mostram a interação sob a perspectiva do usuário, experiências que o usuário possa ou deve ter ao usar um produto, a figura 2 mostra estas metas da experiência do usuário.

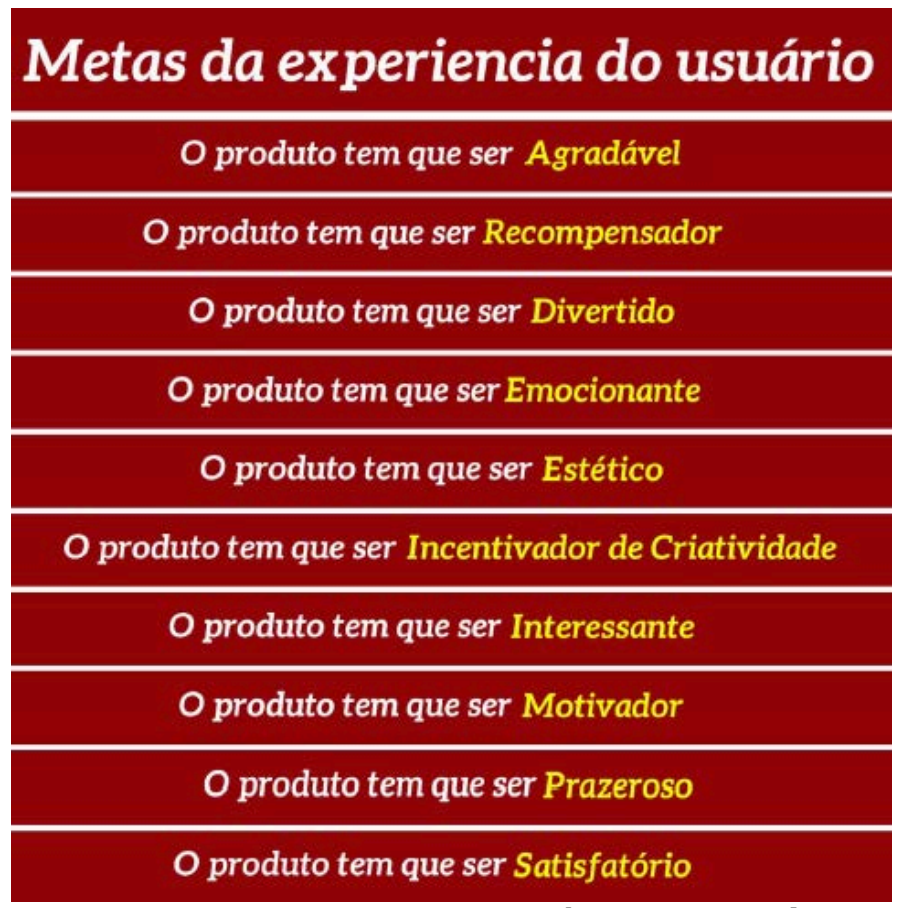

Figura 2: Metas da Experiência do usuário

Fonte: Adaptado de Preece et. al. (2013)

As metas apresentadas na figura 2 vale citar que não são regras a serem seguidas condicionalmente, pois são metas de qualidades subjetivas e procuram saber como o usuário sente o sistema (Preece et. al. 2013). Muitas dessas experiências que conseguimos captar no usuário vêm do seu conhecimento cultural já vivenciado anteriormente e da sua própria mente, produtos, websites, similares em que o usuário já tenha tido certo contato, sendo assim, tendo mais eficácia a interação (Royo, 2008).

Assim essa experiência está relacionada aos sentimentos vivenciados pelas pessoas, com o uso do produto ou interface, sendo uma interação individual para o usuário, portanto não é correto falar que 


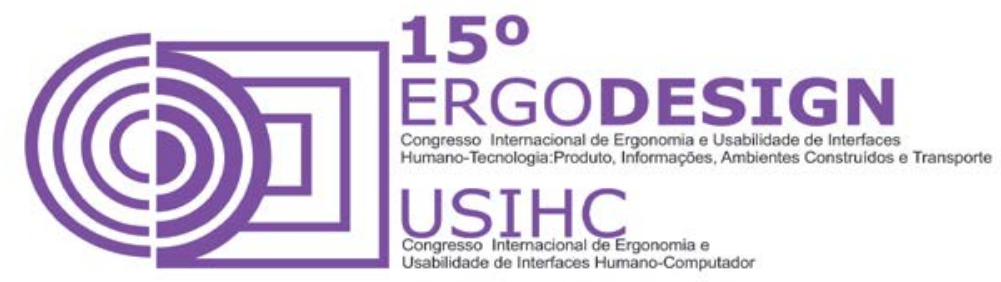

está projetando a experiência do usuário e sim para a experiência do usuário (CYBIS et al., 2010).

Tendo em vista o fato de que a experiência do usuário é o resultado de uma interação entre o usuário e um determinado produto em seu contexto de uso pode se perceber que suas emoções, cultura e a experiência de vida são fatos fundamentais para a criação de um produto ou uma interfase gráfica, e que como mostra a figura $3 \mathrm{em}$ que o usuário geralmente gera uma expectativa antes de usar o produto, uma experiência durante a interação e uma reflexão pós-experiência.

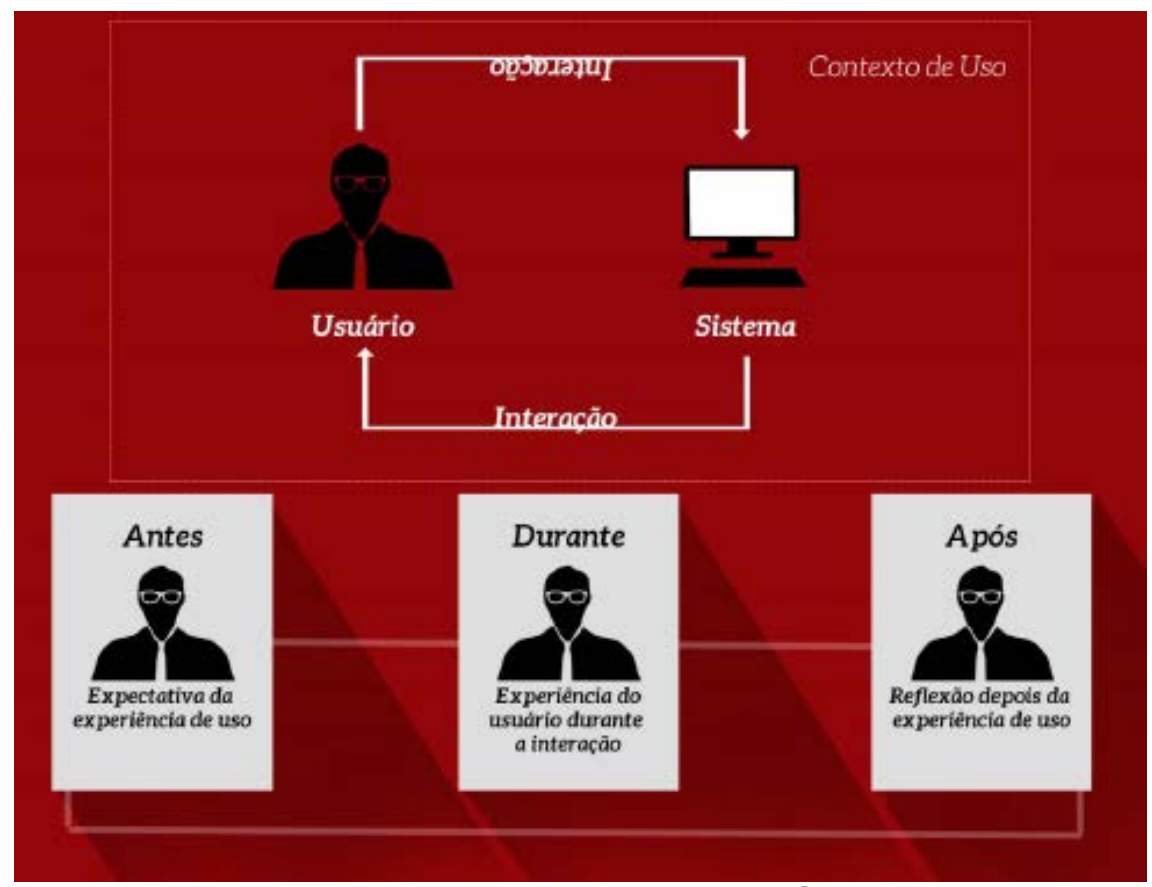

Figura 3 - Esquema de interação, usuário e sistema

Fonte: Desenvolvido pelo autor, adaptado de CYBIS et al. (2010).

Os dados teóricos apresentados pelos autores supracitados mostram que o usuário é uma peça fundamental para a essência de um desenvolvimento projetual e que, para se ter uma boa interação com o usuário, é preciso conhecê-lo e saber da suas necessidades, emoções para que usuário tenha prazer em usar o que lhe foi projetado.

\section{USABILIDADE}

Para facilitar a interação e a experiência do usuário com algum sistema a usabilidade é abordada como um dos principais assuntos. O autor (CYBIS et al., 2010), aborda que a usabilidade é um atributo de qualidade relacionado á facilidade de um sistema interativo ou interface. Conforme a ISO 9241-11(2002), usabilidade são conteúdos capazes de melhorar o uso de um produto com o usuário atingindo os objetivos da eficácia, desempenho e satisfação. A usabilidade é um atributo de qualidade sobre o quão fácil de usar uma interface é para o usuário. (NIELSEN-NORMAN GROUP, 2013, web). 


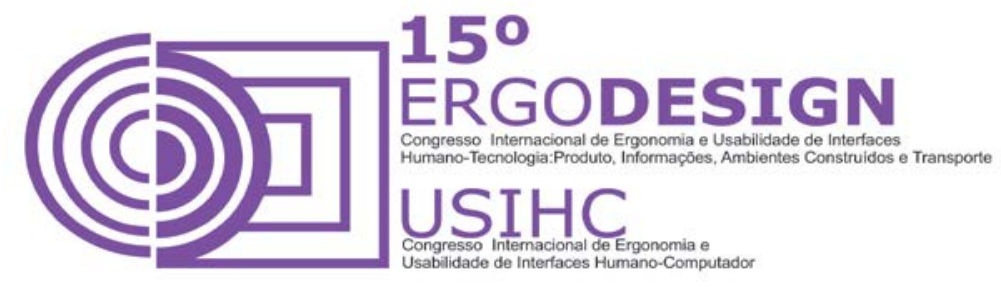

Para o autor Krug (2006) aborda que a usabilidade significa assegurar que uma interface funcione perfeitamente, que uma pessoa leiga possa usar facilmente, para seu propósito, sem ficar frustrada.

Pensando neste sentido, de qualidade e boas experiências para o usuário, percebe-se que uma interface deve ser projeta pensando sempre na facilidade do usuário com a navegação. Conforme Cybis et al. (2010) a construção de uma interface ou um sistema de interação com usabilidade depende de diversas análises cuidadosas de seu contexto de uso e da participação ativa do usuário no projeto.

Portanto a interface de um website deve ser clara e simples de usar proporcionando ao usuário total confiança. Nielsen e Tahir (2002) defendem que os usuários perdem a paciência quando precisam clicar em um link só para saber o que significa e para obter uma informação, por isso, no processo de desenvolvimento de uma interface o usuário deve estar presente participando de cada etapa com isso o projetista conhece melhor pra quem ele está desenvolvendo.

A ergonomia também tem esse viés de proporcionar uma eficácia, eficiência e o bem-estar ao usuário, ela está na origem da usabilidade, isso significa que o seu objetivo é garantir que a interface esteja adaptada há maneira de pensar do usuário e de como ele trabalha, assim, proporcionando uma ótima usabilidade Cybis et al. (2010).

No desenvolvimento de um projeto de interface pode ser utilizado vários tipos de metodologias que auxiliam em um desenvolvimento mais eficiente e eficaz ao qual é definido quais são as necessidades do usuário, seguindo este pensamento Preece et. al. (2013) abordam que para um projeto interativo consiga alcançar as necessidades dos usuários tendo um bom feedback e também dando essa segurança para o usuário, o autor propõe as metas de usabilidade mostradas na fig. 4.

\section{Metas de Usabilidade}

Eficácia: Referece quando o sistema faz o que é esperado.

Eficiente: Auxilia os usuários em suas tarefas permitindo tarefas simples sendo

realizadas em poucas etapas.

Segurança: Possibilita a segurança do usuário protegendo e evitando erros.

Utilidade: Oference a funcionalidade do sistema para que o usuário realize suas tarefas.

Aprendizagem: Facilita a aprendizagem do usuário com o sistema.

Memorização: Possibilita fácil memorização de como utilizar o sistema, depois de já ter aprendido como fazê-lo.

Figura 4: Metas de Usabilidade

Fonte: Adaptado de Preece et al. (2013)

Estas metas apresentadas enfatizam a experiência do usuário, (Preece et. al, 2013) defendem que 


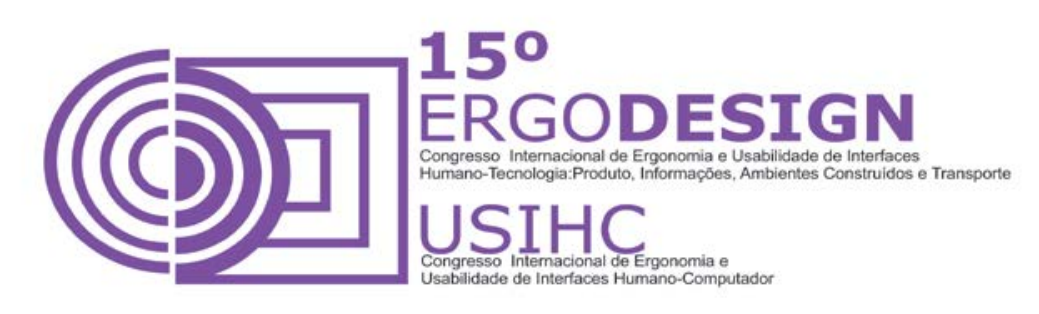

estas metas são fundamentais para o design de interação e elas são feitas por critérios diferentes, estas metas de usabilidade são muito importantes, pois estão dentro da experiência do usuário em seu contexto de uso, como mostra a figura 5.

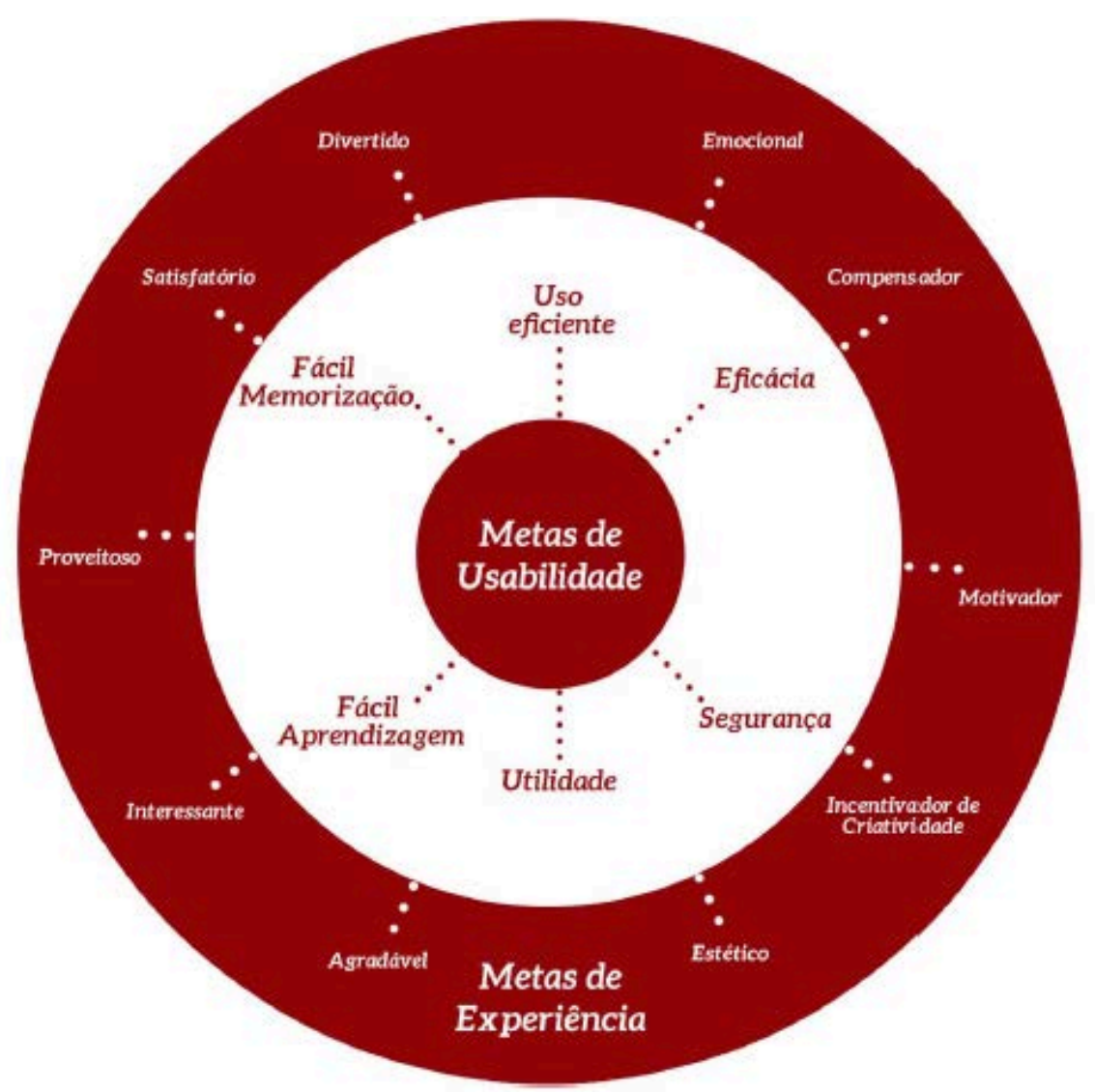

Figura 5: Ligação das metas de Usabilidade

Fonte: Adaptado de Preece et al. (2013)

Como estas metas de usabilidade estão ligadas com as metas de experiência do usuário fazendo relação com a interatividade com o produto, Preece et. al. (2013) fala que se um produto foi desenvolvido com estas qualidades ele está sempre relacionado em melhorar a experiência do usuário. Coelho (2008) afirma que a usabilidade implica que a interface deve ser funcional, sendo fácil para o usuário utilizá-lo, pois a mesma tem muitos objetivos, além da sua funcionalidade.

Nas interfaces mais atuais, o modo como o usuário navega é muito levado em consideração. A usabilidade é requisitada neste parâmetro por estar diretamente ligada na interatividade e com o desempenho da experiência do usuário. 


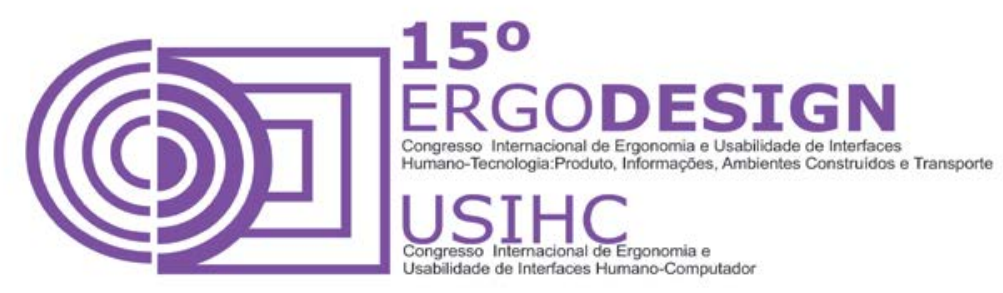

\section{ERGONOMIA COGNITIVA}

A ergonomia cognitiva faz referência aos processos mentais, como a memória, percepção, cognição e a resposta motora, conforme afetam as interações entre um usuário e sua interface. Com a aplicação dos princípios da ergonomia cognitiva pode-se modela a interface com as necessidades dos usuários. (INTERNATIONAL ERGONOMICS ASSOCIATION, 2014; Moraes, 2010; ABERGO, 2014)

Preece et. al. (2013) abordam que a cognição é tudo o que acontece em nossa mente, o que fazemos dela envolve processo cognitivo, como o falar, pensar, aprender, lembrar e tomar decisões. A cognição também pode ser dividida em dois modos, cognição experimental e cognição reflexiva, onde a experimental pode se definir como um estado mental que percebemos, agimos e reagimos do que acontece ao nosso redor sem qualquer esforços e a reflexiva parte para o modo de pensar, comparar e tomar decisões. Na construção de uma interface a ergonomia cognitiva é muito importante, pois tem que levar em consideração e conhecer as habilidades, conhecimentos, carga cultural dos usuários, assim conhecendo o caminho e os objetivos a serem traçados. (Cybis et al. 2010).

Estes processos de cognição devem ser explorados mais especificamente em determinadas variáveis, dependendo muito do projeto a ser executado, Preece et. Al (2013) abordam os processos de atenção, percepção, memória e aprendizado.

- Atenção: Resulta o processo da concentração e da focalização dos processos cognitivos de algum objeto, envolvendo nossos sentidos auditivos e visuais. $\mathrm{Na}$ internet isso é bastante testado com elementos gráficos com cores chamativas e piscando, muitas vezes tirando nossa concentração. (CYBIS, 2010; PREECE et al., 2013).

- Percepção: Refere-se em como uma informação é captada pelos seus órgãos perceptivos, é um processo complexo que envolve outros processos cognitivos como a memória, atenção e a linguagem. Assim formando a percepção humana. (CYBIS, 2010; PREECE et al., 2013).

- Memória: Implica em recordar e memorizar vários tipos de conhecimento, assim sabendo sempre como agir adequadamente, (CYBIS, 2010; PREECE et al., 2013). Ainda Royo (2008) aborda que sempre buscamos recorrer ao conhecimento em nossa memória para agirmos adequadamente nos sites observando as semelhanças com o que já foi aprendido e armazenado.

- Aprendizado: É caracterizado pelas modificações das representações simbólicas já armazenadas em sua memória, sendo que não acontece exclusivamente pelo acumulo de conhecimento, mas também pela eliminação de hipóteses falsas, de restrições inoportunas. (CYBIS, 2010).

Com os dados apresentados pôde-se perceber que a ergonomia cognitiva é muito importante para a construção de uma interface, por reforçar a relevância dos aspectos cognitivos dos usuários, onde possam ser criados elementos que chamem a atenção do usuário, facilitando sua percepção e também sendo de fácil memorização e aprendizado para que tenham uma ótima experiência ao navegarem pela interface. 


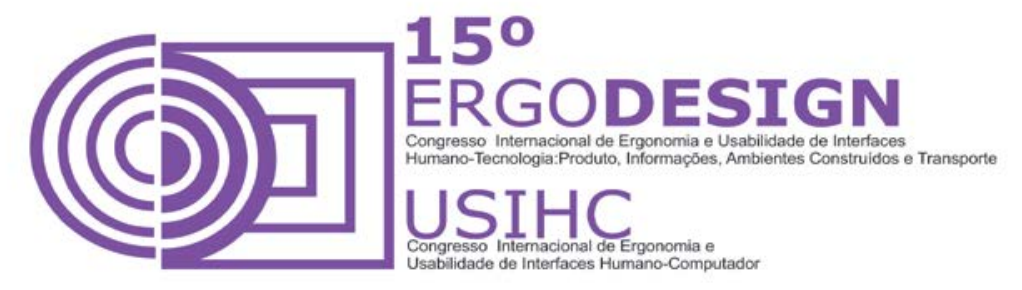

\section{HEDONOMIA}

Como os estudos sobre o usuário estão cada vez mais valorizados, seguindo buscar uma experiência mais sucinta, também uma usabilidade e ergonomia mais aprimorada, ouve-se um interesse em compreender as emoções dos usuários. Norman (2008) aborda que as emoções dos usuários tem total ligação com a cognição, que as emoções refletem em como pensamos, agimos e decidimos. Ainda o autor aborda que as interfaces podem evocar emoções muito fortes e positivas, tais como amor, apego, felicidade e prazer.

Seguindo com essa linha do design emocional, um ramo de estudo focado na promoção do prazer e a interação entre humano-tecnologia é a hedonomia, promovendo o prazer na interação com os produtos (CYBIS, 2010; HANCOCK et al., 2005).

Sendo uma disciplina bem próxima da ergonomia que busca prevenções com o desconforto, dores e frustações, as duas disciplinas, tanto a hedonomia como a ergonomia buscam o mesmo objetivo de aperfeiçoar a interação humano-tecnologia (Cybis et al. 2010). Ainda sobre esse viés de ergonomia e hedonomia, a autora MONT'ALVÃO, (2008) aborda que é justamente no limiar da usabilidade que as duas disciplinas se misturam.

Buscando esse aperfeiçoamento na hierarquização que se baseia na pirâmide de Maslow, figura 6, que segundo o qual o usuário é motivado por necessidades organizadas hierarquicamente em níveis, desta forma o usuário só passa para necessidade do nível superior, quando a necessidade do nível inferior estiver satisfeita. (Cybis et al. 2010).

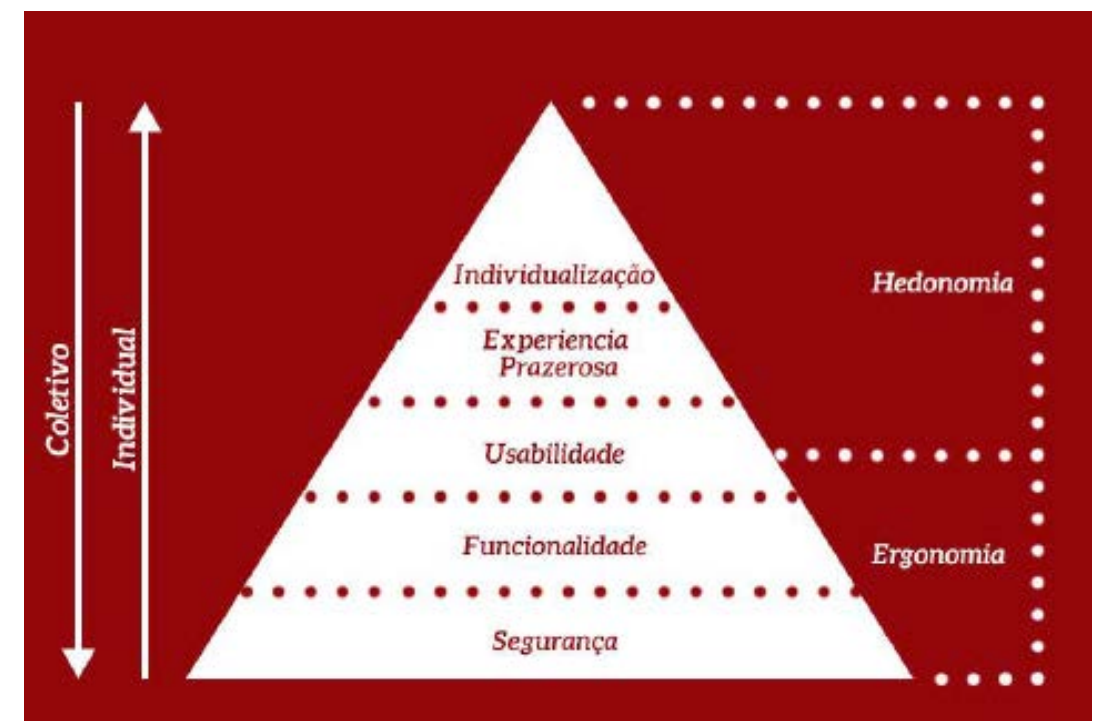

Figura 6: Pirâmide de Maslow: Ergonomia e Hedonomia

Fonte: Desenvolvido pelo autor, adaptado de Hancock et al. (2005).

Seguindo essas necessidades de hierarquização na interação humano-tecnologia, a interface deve ser projetada primeiramente para ser segura em seu uso e nas informações de dados dos usuários, a interface passando essa segurança a necessidade passa para o segundo nível e assim 


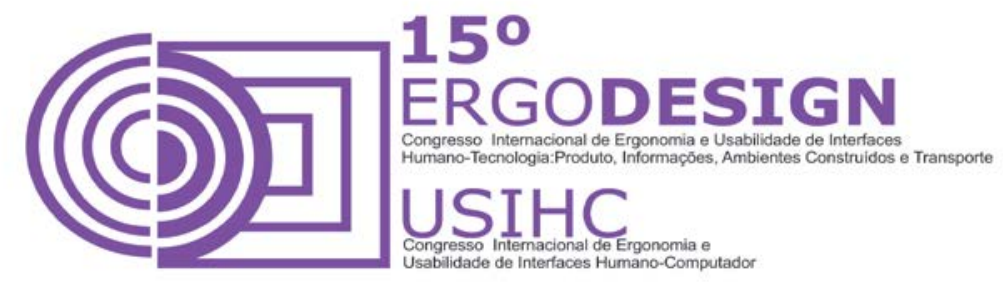

sucessivamente, até chegar ao último nível já tendo uma experiência prazerosa, permitindo que o usuário tenha a sensação de estar no comando do sistema. (Cybis et al. 2010).

Para conseguir encontrar essa necessidade e conseguir satisfazer o usuário Norman (2008) aborda que a melhor maneira é pela observação onde você está em contato direto com o usuário, para que tenha bons resultados, a observação deve ocorrer quando o usuário esteja interagindo naturalmente com a interface. Tais questões abordadas são muito importantes para a observação das necessidades dos usuários transformarem o projeto em uma interface prazerosa e que traga muitas experiências boas para o usuário.

\section{INTERAÇÃO}

Com a tecnologia digital evoluindo cada vez mais rápido, houve uma preocupação maior em desenvolver produtos mais interativos pensando na experiência em que o usuário terá. Com essa tamanha evolução a definição evolui ao longo do tempo, pois antes se tratava de uma sequência de estímulos e respostas com a interação de corpos físicos, com o surgimento das pesquisas cognitivas passou-se a falar que o design de interação significa melhorar e ampliar a experiência do usuário, conforme eles trabalham, se comunicam, e interagem com uma interface (Preece et. a., 2013; Barbosa, 2010; Garret, 2011).

Para Saffer (2010) design de interação é uma ciência que tem a preocupação com da arquitetura física, ou seja, a sua forma de uso e a relação da experiência do usuário com uma interface. Design de interação trabalha junto com diversas outras disciplinas como arquitetura de informação, design de produto, design gráfico, ergonomia, experiência do usuário entre outras, assim tornando o projeto mais diversificado, harmônico e eficaz como demonstrado na figura 7. Mas cada uma com sua particularidade e objetivo principal. (Preece et. al, 2013)

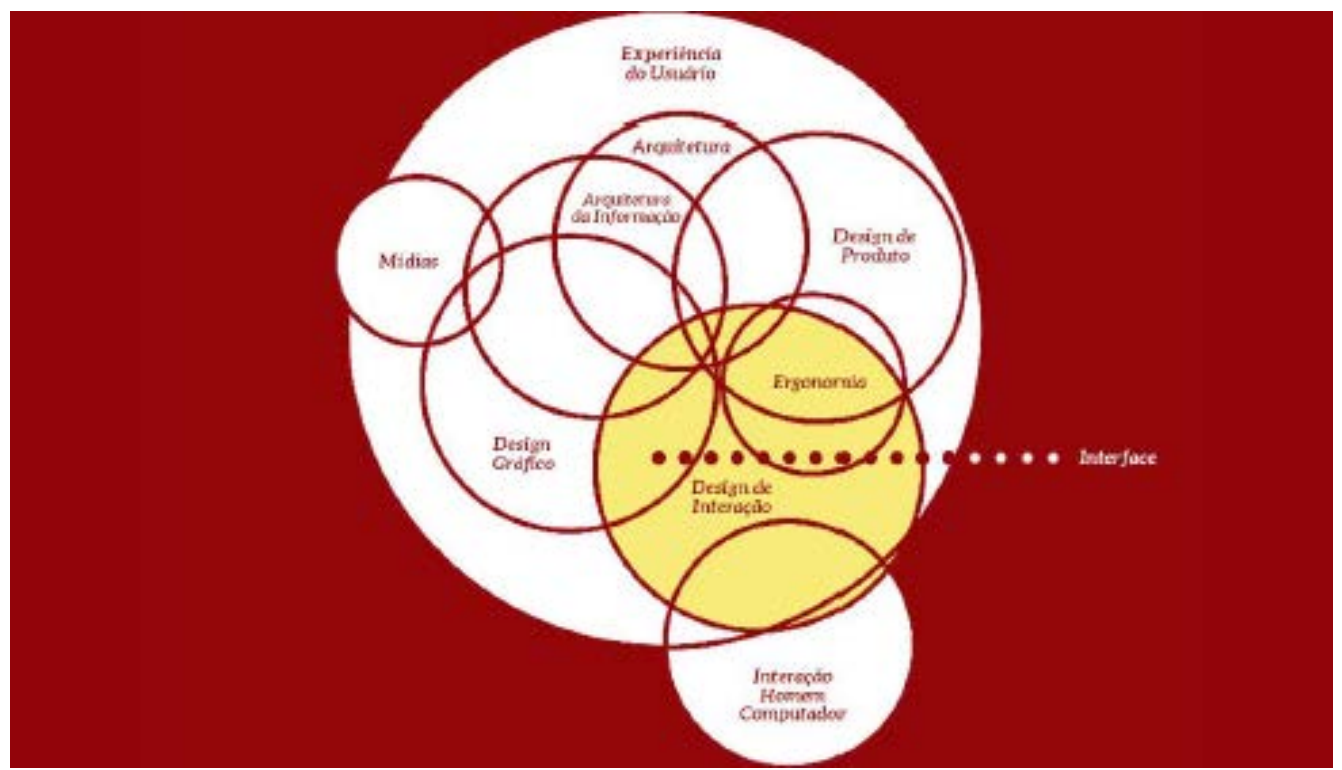

Figura 7: Relação entre as disciplinas com o design de interação

Fonte: Desenvolvido pelo autor, adaptado de Saffer (2010). 40 


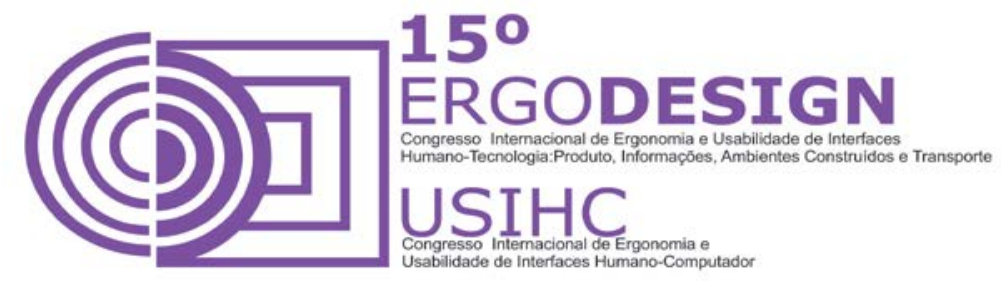

Assim compreendendo que todas englobam parcialmente a disciplina experiência do usuário, sendo uma das principais relações entre estas disciplinas, dando para perceber que uma complementa a outra, estando em harmonia (SAFFER, 2010). Portanto, colocando em mais evidência a importância de levar em consideração desenvolver projetos pensando na experiência do usuário, o sucesso virá com mais êxito.

Com essa ideia de interação entre usuário e sistema, interface, (Barbosa, 2010 apud KAMMERSGAARD, 1988) identica quatro perspectivas que cada uma delas atribui ao usuário e ao sistema, determinados tipos de papel e diferentes pontos de vista em sua interação, como demonstra a figura 8 , ilustrada a seguir.
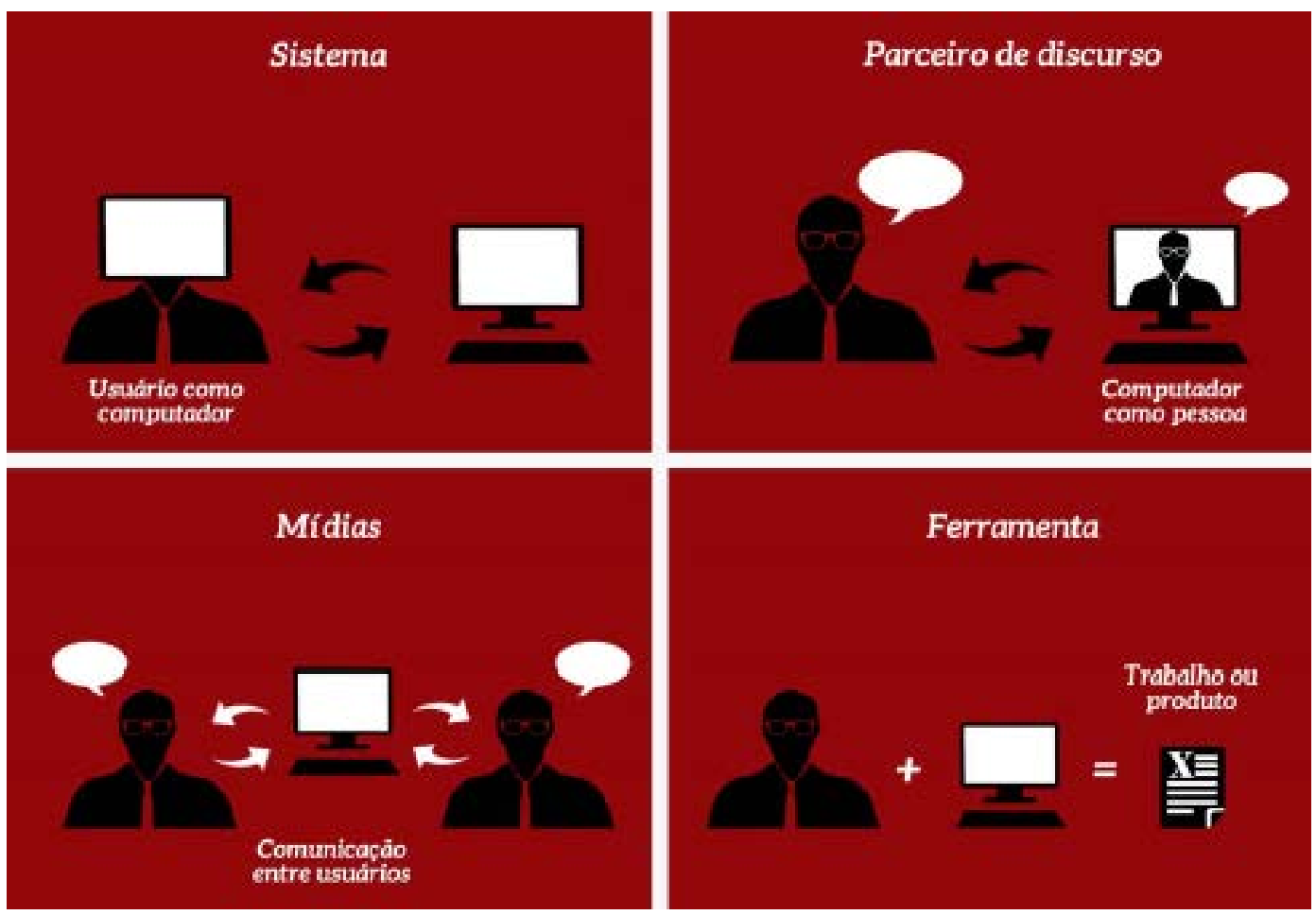

Figura 8: Perspectiva de interação

Fonte: Desenvolvido pelo autor, adaptado de Barbosa (2010).

Em nossos dias atuais estas quatro perspectivas são muito usadas, tanto para trabalho como para entretenimento, determinando o papel do usuário para a realização da interação, apresenta-se a seguir a contextualização das perspectivas mostradas na figura 8.

- Sistema: Refere-se no usuário como computador, ou seja, desse modo o usuário se comporta como uma verdadeira máquina com transmissão de dados entre sistemas, usuário tem menos tempo de interação e menos porcentagem de erros (BARBOSA, 2010).

- Parceiro de Discurso: Esta perspectiva visa tornar a interação do homem com computador ou interface, mais próxima de uma interação entre seres humanos, o sistema deve participar 


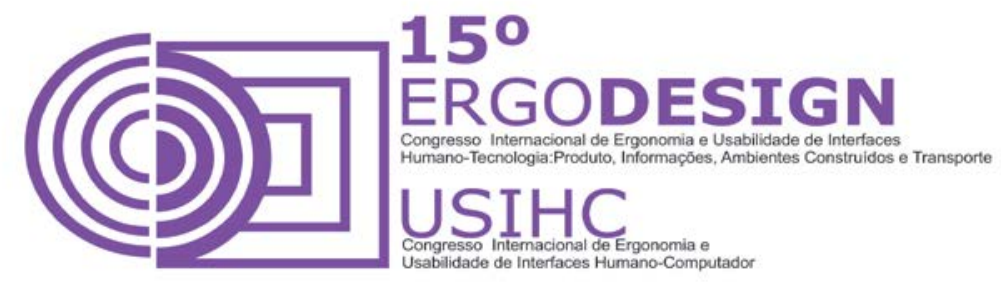

interagindo com o usuário de uma forma como se fosse um ser humano, tomando decisões, raciocinando, conversando, entre outros (BARBOSA, 2010).

- Ferramenta: Seu sistema interativo é considerado um instrumento que auxilia o usuário a desenvolver seus trabalhos e tarefas, esta ferramenta terá sucesso dependendo do conhecimento que o usuário tem sobre a ferramenta, assim sua funcionalidade é baseada na experiência que o usuário já tenha adquirido (BARBOSA, 2010).

- Mídias: Esta perspectiva vem ganhando mais destaques recentemente com a interação gerada pela internet com o usuário, pois o usuário se comunica através de um sistema mediador, com outros usuários (BARBOSA, 2010).

Buscando encontrar uma melhor forma de interação, na qual o usuário seja beneficiado e que sua experiência seja positiva, Preece et. Al, (2013) aborda sobre quatro atividades básicas para o processo de design de interação, onde estas atividades serão para mostrar se a interface será de fácil uso, medir a usabilidade ou se os requisitos foram atendidos, conforme figura 9.

\section{Processo de Interação}

Requisitos: Define e identifica as necessidades dos usuários e projeta requisitos de projeto.

Alternativa: Cria alternativas para o projeto, definindo sua parte estética e funcional.

Prototipação: Depois de desenvolvido na etapa anterior é elaborado um protótipo interativo.

Avaliação: Analisa os requísitos e revisa se todas as etapas estão de acordo com o projeto.

Figura 9: Processo do design de interação.

Fonte: Adaptado de Preece et al. (2013).

Ainda com base no texto das autoras é reforçado que o desenvolvimento do projeto deve ser sempre centrado no usuário, ou seja, envolver o usuário no projeto, buscando compreender todas as suas necessidades e buscar compreender como eles agem, interagem uma com as outras, compreender sua cultura e suas diferenças, tendo o pensamento que o projeto deve ser projetado para diversos tipos de usuários, que buscam uma interação que os envolva e traga experiências positivas. 


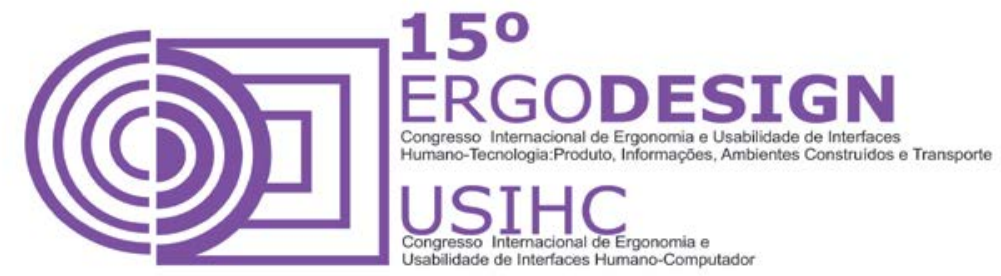

Com os conhecimentos adquiridos sobre design de interação, pode-se perceber o quanto o usuário sempre é a chave principal, mostrando que deve sempre definir todos os requisitos e também para que tipo de usuário o projeto será desenvolvido, qual será o papel do dele na interação, delimitar estas metas para que o mesmo tenha total conforto na sua navegação.

\section{REFERÊNCIAS BIBLIOGRÁFICAS}

ABERGO, Associação Brasileira de Ergonomia. In: www.abergo.org.br.

BARBOSA, S. D. J.; SILVA, B. S. Interação Humano-Computador. Rio de Janeiro: Elsevier. 2010.

CYBIS, Walter de Abreu; BETIOL, Adriana Holtz; FAUST, Richard. Ergonomia e Usabilidade: conhecimentos, métodos e aplicações. São Paulo: Novatec, 2010

GARRETT, Jesse James. The Elements of User Experience: user-centered design for the web and beyond. 2. Ed. Berkley: New Riders, 2011.

HANCOCK, P.A., et al. Hedonomics: The power of positive and pleasurable ergonomics. Ergonomics in Design, Winter, v.13, n. 1, p.8-14. 2005.

INTERNATIONAL ERGONOMICS ASSOCIATION - IEA. Definition of Ergonomics, 2000. Disponível em: <http://www.iea.cc/01_what/What\%20is\%20Ergonomics.html>.

KRUG, Steve. Não me faça pensar: Uma abordagem de bom senso à usabilidade web. Rio de Janeiro, AltaBooks, 2008

MONT'ALVÃO, C. R. Hedonomia, Ergonomia Afetiva: afinal, do que estamos falando?. In: MONT'ALVÃO, C. R.; DAMAZIO, V. Design Ergonomia Emoção. 1. Ed. Rio de Janeiro: FAPERJ/ MAUAD $\mathrm{X}, 2008$, v. 1, p. $19-30$

NIELSEN, Jakob; TAHIR, Marie. Homepage: 50 websites desconstruídos. Rio de Janeiro: Campus, 2002.

NIELSEN-NORMAN GROUP, User Experience (UX) - Our Definition. Disponível em: < http://www.nngroup.com/about-user-experience-definition/>.

PREECE, J. et al. Design de Interação: além da interação homem-computador. 3. Ed. Porto Alegre: Bookman, 2013.

ROYO, Javier. Design digital. São Paulo: Rosari, 2008

SAFFER, Dan. Designing for Interaction: Creating Innovative Applications and Devices, 2. Ed. Berkeley, CA: New Riders. 2010. 